\title{
Ontogenetic differences in conditioning to context and CS as a function of context saliency and CS-US interval
}

\author{
DAVID L. MCKINZIE and NORMAN E. SPEAR \\ State University of New York, Binghamton, New York
}

\begin{abstract}
A series of experiments examined ontogenetically the effects of context saliency and CS-US interval on the learning of CS-US and context-US associations. Although adult rats generally showed an inverse relationship between CS and context learning that depended upon CS-US interval and context saliency, the opposite relationship held for preweanlings. Consistent with many contemporary learning theories, adult rats expressed CS-context competition in learning about the US. Preweanlings, on the other hand, exhibited potentiated responding to either the context or the CS as a result of strong learning about the other element. These results suggest that adult and infant rats process information in a qualitatively different manner.
\end{abstract}

Infants and adults may process information in a qualitatively different manner. For example, young animals do not show adults' inclination for overshadowing when they are tested on a single element of a compound training stimulus (Kraemer, Lariviere, \& Spear, 1988; Mellon, Kraemer, \& Spear, 1991) but rather show potentiation, the opposite of overshadowing (Hinderliter \& Misanin, 1988; Kucharski \& Spear, 1985; Spear \& Kucharski, 1984). Age-related differences also exist in the treatment of contextual stimuli (Lariviere, Chen, \& Spear, 1990; McKinzie, Lee, Bronfen, Spear, \& Spear, 1994; Solheim, Hensler, \& Spear, 1980). For example, McKinzie and Spear (1991) found that preweanling rats expressed strong learning to both context and tone following tone-footshock pairings. Context conditioning in animals given pairings of a conditional stimulus (CS) and an unconditional stimulus (US) exceeded that in preweanlings given unpaired presentations of the same events. Thus, pairing of a tone CS with the US potentiated responding to the context (see also Goodwin et al., 1992).

Adults are more likely to attend to stimuli in the selective manner indicative of overshadowing. Punctate CSs usually are chosen for their capacity to elicit an orienting reflex (Pavlov, 1927) and, therefore, are likely to overshadow contextual stimuli in a typical conditioning experiment. Associative competition between the context and CS occurs in procedures that vary contingency and contiguity of the CS-US relationship. For example,

This research was supported by NIMH Grant 5R37MH35219 to N.E.S. D.L.M. is now at the Indiana School of Medicine, Department of Psychiatry, 791 Union Drive, Indianapolis, IN 46202. Correspondence concerning this article should be addressed to N. E. Spear, Center for Developmental Psychobiology, Department of Psychology, Binghamton University, Binghamton, NY 13902.

-Accepted by previous editor, Vincent M. LoLordo
Odling-Smee (1975) found that, as CS-US contingency decreased, conditioning to the training context increased. Marlin (1981) found that an inverse relationship existed between context and CS learning as a function of CS-US interval. When the CS and US were temporally contiguous, responding to the CS overshadowed responding to the context. As CS-US interval increased, however, conditioning to the CS diminished, while context learning increased. At an intermediate trace interval, conditioning occurred to both the context and the CS, whereas only context conditioning occurred at long CS-US intervals. Marlin concluded that both context and CS stimuli potentially form associations with the US and that learning occurs to the better predictor of the forthcoming US.

The purpose of the present series of experiments was to examine ontogenetically the effects of context saliency and CS-US interval on context and CS learning. The hypothesis was that adult rats would show context-CS competition as a function of context saliency and CS-US interval. Specifically, CS conditioning should be strongest when training occurs in a "plain" context with a short CS-US interval. Preweanlings, on the other hand, were expected to treat the context and $\mathrm{CS}$ as a stimulus compound, thus yielding a direct relationship between degree of conditioning to the context and that to the CS. Moreover, we expected the strongest context and CS learning to occur for preweanlings when they were trained in an "enhanced" context and with a short CS-US interval.

\section{EXPERIMENT 1A Adults}

The purpose of Experiment 1 was to determine whether context complexity or saliency influences the relationship identified by Marlin (1981). Adult rats re- 
ceived tone-footshock presentations in a "plain" or an "enhanced" context. Rats received CS-US pairings either with a 0 - or an 80 -sec interstimulus interval (ISI; measured from CS offset to US onset) or with the CS and US in a quasi-random unpaired relation. The 80-sec ISI was established in pilot experiments to yield a moderate level of conditioning in adults under the present procedure but less conditioning than occurs with a 0 -sec ISI. Additionally, another control group received the USs in a distinctly different context and served as a comparison group for assessing context conditioning. Testing occurred $24 \mathrm{~h}$ later in the context in which the CS had been presented during conditioning. Conditioned suppression of activity has been found to be a reliable indicator of fear conditioning and was used here (Bolles \& Collier, 1976; Fanselow, 1980).

We expected that adults would exhibit less conditioning to the CS and more conditioning to the context with increasing trace intervals, such that the group trained with the 80-sec ISI would show both context and CS conditioning (see Marlin, 1981). Additionally, the ability of the context to overshadow CS conditioning was expected to be more pronounced when training occurred in the enhanced context.

\section{Method}

Subjects. Ninety-six ( $n=10-12$ per group) adult male and female Sprague-Dawley rats (90-120 days of age) were weaned at 21 days of age and housed ( $n=6$ per cage) in hanging wiremesh cages $(63 \times 24 \times 17 \mathrm{~cm})$. The rats were housed in a temperature-controlled colony room maintained on a $16: 8$-h light:dark cycle, with light onset occurring at $0600 \mathrm{~h}$. Food and water were freely available. The experiment was conducted during the light portion of the light:dark cycle.

Apparatus. The plain context was located within a white $(54 \times$ $40 \times 46 \mathrm{~cm})$ sound-insulated box. A shock grid $(38 \times 30.5 \times$ $7 \mathrm{~cm}$ ) rested upon the compartment floor. The grid bars were $3 \mathrm{~mm}$ in diameter and spaced $1 \mathrm{~cm}$ apart from adjacent grid bars. A shock generator (Grason-Stadler) provided a 1-mA scrambled footshock that lasted $0.5 \mathrm{sec}$. The CS, as measured from the grid floor, was a $15-\mathrm{sec}, 79-\mathrm{dB}$ (A-scale), 2000-Hz tone. Tone delivery originated from three speakers situated $34 \mathrm{~cm}$ above the grid floor. Clean newspapers were placed under the shock grid and changed after each experimental session. A ventilation fan provided background noise at $72 \mathrm{~dB}$. A $1.5-\mathrm{W}$ houselight centered on the right wall and situated $34 \mathrm{~cm}$ from the chamber floor provided dim ambient light throughout each session. A $28 \times 20.5 \times 25.5 \mathrm{~cm}$ black Plexiglas chamber, which was partitioned into two equally sized compartments, served as the conditioning chamber and rested upon the grid floor. Placement of a wire-mesh screen on top of the chamber prevented the rats from escaping from the context.

The enhanced context was located in the same room as was the plain context and utilized the same equipment with the following additions: (1) three frosted 7.5 -W light bulbs located $29 \mathrm{~cm}$ above the grid floor flashed on $(0.5 \mathrm{sec})$ and off $(0.5 \mathrm{sec})$ throughout the experimental session, and (2) $1 \mathrm{cc}$ of commercially available lemon odor (Humco) was distributed evenly beneath the shock grid on a $20 \times 10 \mathrm{~cm}$ strip of cotton. The odor and cotton were changed after each experimental session.

The control context was located in another room and consisted of a large, white, sound-attenuating chamber that had the same physical dimensions as the plain and enhanced chambers. A $38 \times$ $30 \times 7 \mathrm{~cm}$ shock grid rested upon the compartment floor. The grid bars were $3 \mathrm{~mm}$ in diameter and spaced $3.5 \mathrm{~mm}$ apart center to center. A clear $28 \times 20.5 \times 25.5 \mathrm{~cm}$ Plexiglas chamber was placed upon the shock grid. The chamber was unlike the one in the other contexts in that it was clear and was partitioned into three equally sized compartments. The rats were placed in the two outer compartments, and pink construction paper was attached to the walls of the middle compartment. The chamber door was left open, exposing the rats to ambient room lighting. A fine wire-mesh screen covered the top of the Plexiglas chamber.

Testing occurred in the same context in which the CS had been presented during conditioning (viz., either the plain or the enhanced context). The test chamber was identical to the conditioning compartment except for the addition of two circular disks $(2.5 \mathrm{~cm}$ in diameter) that were centered $1.5 \mathrm{~cm}$ from the grid floor and spaced $4.0 \mathrm{~cm}$ apart. These disks were the transmitter and receiver for an ultrasonic activity-monitoring device (Moye \& Rudy, 1985). Any movement within the chamber resulted in frequency discrepancies detected by the receiver. Each frequency discrepancy resulted in a closure of an electromechanical relay, which was termed 1 activity count. The sensitivity and reliability of the device was adjusted and checked periodically with the aid of a metronome.

Procedure. Adult rats were assigned randomly to one of eight groups (context controls, unpaired [UP], 0-sec, or 80-sec ISI groups for plain or enhanced contexts). During training, we exposed each group to three experimental phases separated by $40 \mathrm{~min}$. The rats first received $40 \mathrm{~min}$ of exposure to either the plain or the enhanced context (counterbalanced) and were then placed in a holding cage for $40 \mathrm{~min}$. Next, the rats were given $40 \mathrm{~min}$ of exposure to the control context (UP, $0-\mathrm{sec}$, and $80-\mathrm{sec}$ ISI groups). Context controls received eight US-only presentations on a variable time (VT) 5-min schedule during this phase. All rats were again returned to holding cages for $40 \mathrm{~min}$. In the final phase, the UP, 0 -sec, and 80-sec ISI groups received eight CS presentations on a VT 5-min schedule in the context to which they had yet to be exposed (plain or enhanced). The US was presented (1) immediately following the CS in the 0 -sec ISI condition, (2) $80 \mathrm{sec}$ after the CS in the 80-sec ISI condition, or (3) on a random schedule with the constraint that a US never occurred within $100 \mathrm{sec}$ of the CS in the UP condition. The context control group received eight CS-only presentations on the same temporal schedule as did experimental animals. Thus, all rats were exposed to all three contexts before testing - for example, if the first exposure occurred in the plain context, Phase 3 training occurred in the enhanced context (and vice versa), with exposure to the control context occurring in the interpolated phase.

The rats were individually tested $24 \mathrm{~h}$ later in the context in which the CS had been presented. Testing consisted of placing a rat into the test chamber for a 1-min adaptation period. Following the adaptation period, the latency to reach a total of 200 activity counts (measured in 25-count blocks) was recorded both prior to and during a CS presentation.

We used the latency to emit the first 100 activity counts in the test context as a measure of context conditioning, with longer latencies indicating stronger conditioning. A suppression score based on the following formula was used to assess CS conditioning: Baseline (second 100 pre-CS counts) latency divided by the sum of the latencies to the first 100 activity counts during the CS and the pre-CS baseline. This measure corrects for the use of latencies (as opposed to a direct measure of activity) such that the suppression score is equivalent to a standard Annau and Kamin (1961) suppression ratio. Thus, a suppression score of 0.5 indicates no change in activity during CS presentations relative to the pre-CS baseline. Lower scores indicate greater suppression of activity (and greater conditioning) to the CS. Comparable pre-CS baseline activity across groups was inferred if no group differences occurred in the time to reach 100 activity counts prior to a tone presentation. In cases where pre-CS baseline activity differed across groups, the last 25-count block was compared with each 
preceding 25-count block. Less than a $15 \%$ change in latency from the last pre-CS block was used as a criterion for a stable baseline. The number of sequential 25 -count blocks that met this criterion were then used as the baseline in the computation of suppression scores.

Log transformations were used on all latency scores to normalize the sample distribution. An analysis of variance (ANOVA) was conducted on both latency and suppression scores. Fisher tests (Keppel, 1982) were performed on any significant main effects or interactions. When evaluating tone conditioning, the context control group was omitted from the analysis, and the UP group was used as the comparison group for significant conditioning.

\section{Results and Discussion}

Context conditioning. Figure 1 shows mean times to the activity criterion during the pre-CS period in each of the eight groups. Context conditioning occurred in the UP and 80 -sec trace groups, regardless of whether training occurred in the plain or enhanced context. However, when the CS and US were contiguous ( 0 -sec trace interval), context conditioning occurred only in the enhanced context.

A two-factor ANOVA (context $\times$ group) yielded significant main effects of context $[F(1,88)=54.43, p<$ $.0001]$ and group $[F(3,88)=20.22, p<.0001]$, as well as a significant interaction $[F(3,88)=4.94, p<.003]$. With respect to the context $\times$ group interaction, a Fisher test revealed that only the UP and 80-sec trace groups differed from their context control group when training and testing occurred in the plain context. The UP group

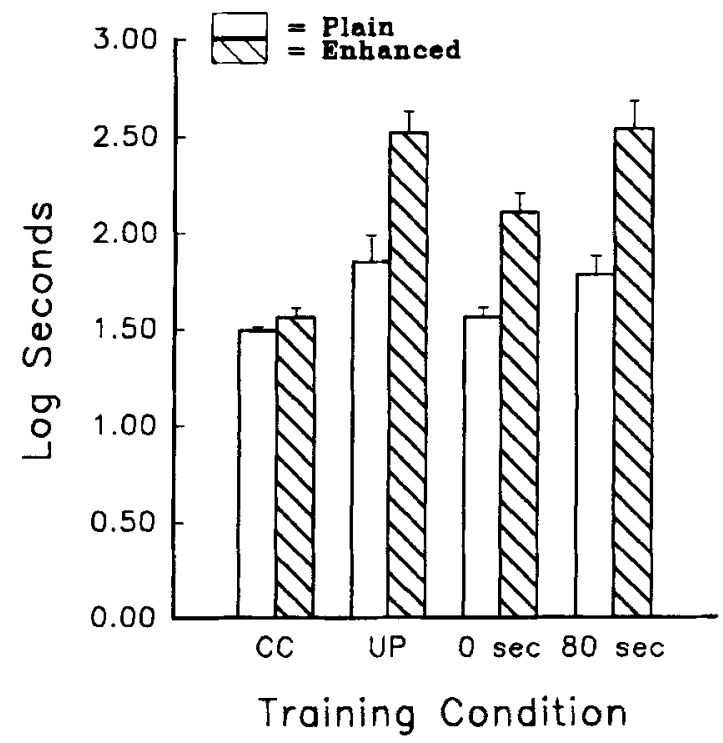

Figure 1. Mean time (log sec) to reach the first 100 pre-CS activity counts as a function of CS-US interval and context saliency in adult rats. Training consisted of eight $C S$ and US presentations. Testing occurred $24 \mathrm{~h}$ later. The difference between context control (CC) groups and unpaired (UP), 0-sec, and 80-sec trace groups represents the degree of context conditioning. Higher latency values denote greater context conditioning. Vertical lines represent standard errors of the mean. also took longer to reach criterion than did the 0 -sec trace group. In the enhanced-context condition, the 0 sec, 80-sec, and UP groups had longer latencies to reach criterion than did context controls. The UP and $80-\mathrm{sec}$ trace groups had longer latencies than did the 0 -sec trace group. A comparison of groups across context conditions indicated that CS-US pairings or UP treatment in the enhanced context produced longer latencies than did similar treatment in the plain context.

To summarize context learning, experimental groups trained in the enhanced context took consistently longer to reach criterion than did those trained in the plain context, indicating greater context conditioning in the enhanced-context condition. Consistent with the findings of Marlin (1981), context conditioning tended to be most prominent when the CS and US were not temporally contiguous (UP and $80-\mathrm{sec}$ groups). It is important to note that the context control groups did not differ in the plain and enhanced contexts, ruling out the possibility that longer latencies in the experimental groups trained in the enhanced context resulted from any nonassociative influence of context saliency.

CS conditioning. A two-factor ANOVA (context $x$ group) of latencies to reach 100 activity counts prior to CS onset (baseline period) yielded main effects of context $[F(1,88)=16.13, p<.001]$ and group $[F(3,88)=$ $11.27, p<.0001]$. Thus, this extended pre-CS baseline period was not deemed sufficiently stable across groups to compute suppression scores. To determine baseline stability within each group, the last 25 -count pre-CS block was compared with each of the previous blocks using the $15 \%$ change criterion. Using this moderately conservative criterion, the last 50 pre-CS counts were found to be stable in all groups. Therefore, suppression scores were calculated using this measure as the baseline.

Figure 2 shows suppression scores for CS conditioning as a function of ISI group and context condition. Strong CS learning was evident when training occurred with a 0 -sec trace interval, regardless of context saliency. However, when an $80-\mathrm{sec}$ trace interval occurred between CS termination and US onset, CS learning was evident only in the plain-context condition. Thus, when a long CS-US trace interval was used during conditioning, an enhanced context overshadowed conditioning to the CS.

A two-factor ANOVA (context $\times$ group) of suppression scores yielded only a main effect of group $[F(2,66)=39.35, p<.0001]$. A subsequent Fisher test determined that the 0 -sec ISI groups expressed greater CS conditioning than did either the UP or the 80 -sec trace groups, regardless of context saliency.

Because a significant interaction in the analysis of CS conditioning was not obtained, conclusions concerning the $80-\mathrm{sec}$ trace groups must be qualified. Although the 80 -sec trace condition did not differ from the UP condition when scores were collapsed across context saliency, CS conditioning was evident when training occurred in the plain context. This observation was supported by a 


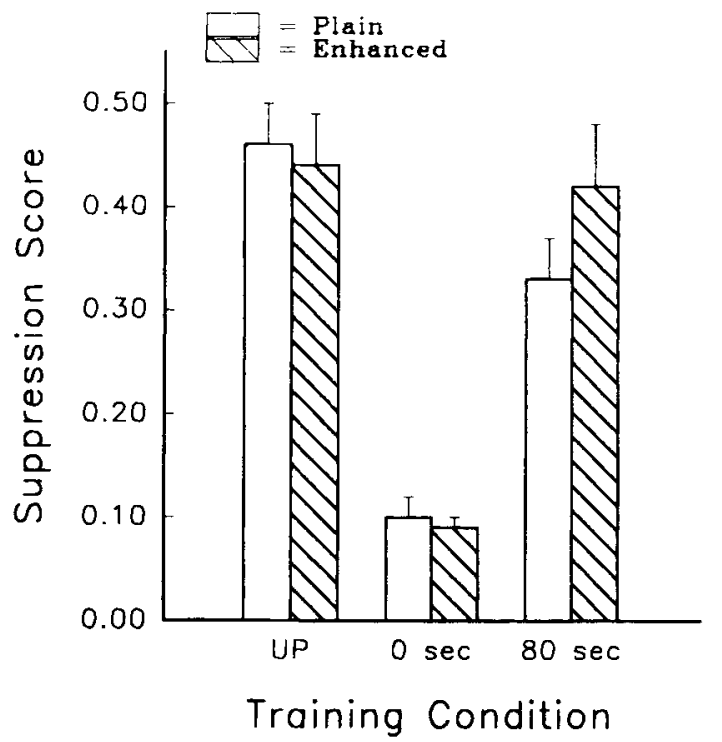

Figure 2. Suppression score conversions of the first $100 \mathrm{CS}$ activity counts as a function of CS-US interval and context saliency in adult rats. Training consisted of eight $C S$ and US presentations. Testing occurred $24 \mathrm{~h}$ later. The difference between unpaired (UP) and trace interval (0-sec and 80-sec) groups represents the degree of CS conditioning. Lower suppression scores denote greater conditioning to the CS. Vertical lines represent standard errors of the mean.

planned comparison $(\alpha=.05)$ indicating that the $80-\mathrm{sec}$ trace group that was trained in the plain context differed from its UP group, an effect not found when training occurred in the enhanced context.

CS-US and context-US associations. Rats trained with UP or 80 -sec CS - US intervals expressed greater context conditioning than did 0 -sec trace groups. Stronger context conditioning generally occurred in the enhanced context. Whereas 0 -sec trace groups showed significant CS conditioning regardless of training context, rats trained with an 80 -sec trace showed conditioning to the CS only in the plain context.

\section{EXPERIMENT 1B Preweanlings}

If younger animals have a relatively strong tendency to configure or unitize elements of the training episode (see Mellon et al., 1991; Spear, Kraemer, Molina, Smoller, 1988; Spear \& Kucharski, 1984; Spear \& Molina, 1987) and to form associations involving the context (Lariviere et al., 1990), then CS and context learning might be expected to show a direct relationship, rather than the inverse relationship seen in adults. Moreover, given a preweanling's greater sensitivity to stimulus intensity (Mellon et al., 1991), increasing the saliency or perceived intensity of one of the conditioning components (i.e., the context) might be expected to additionally promote a strong context-US association. This tendency should be reflected in stronger conditioning to both the CS and the context.
The purpose of Experiment $1 \mathrm{~B}$ was to examine the influence of context saliency and CS-US interval on CS and context learning in preweanling rats. As in Experiment $1 \mathrm{~A}$, eight training conditions were examined. Seventeen-day-old rats were trained with a 0 - or a $20-\mathrm{sec}$ ISI, unpaired (UP) CS-US presentations, or received CSs and USs in distinctly different contexts (context controls). Each of these groups was trained in either a plain or enhanced context. Conditioning to the context and CS was assessed $24 \mathrm{~h}$ later.

\section{Method}

Subjects and Apparatus. Ninety-six male and female 17-dayold Sprague-Dawley rats, which were born and reared in our colony at Binghamton University, were housed with their parents and littermates in standard opaque maternity cages partially filled with pine shavings. Six litters were represented in each group $(n=12)$. The maternity cages were maintained in the same climate-controlled colony room as were the rats in Experiment $1 \mathrm{~A}$.

The apparatus was identical to that used in Experiment 1A, with the exception that pine shavings from the home cage (instead of clean newspapers) were placed underneath the shock grid in the plain context. The sensitivity of the activity monitor also was adjusted until activity levels of naive 17-day-old pups approximated that of naive adults during a 5 -min period in order to equate sensitivity as a function of body mass.

Procedure. Preweanling rats were assigned randomly to one of eight groups of 12 rats each. The procedure of Experiment 1 A was again used here with the following exception: The intermediate CS-US condition (80-sec ISI in Experiment IA) was changed to $20 \mathrm{sec}$ for preweanlings. Animals of this age do not tolerate trace intervals as well as adults do (see Moye \& Rudy, 1987). Pilot studies indicated that a $20-\mathrm{sec}$ ISI resulted in CS conditioning comparable to that seen in adults with the current parameters. Thus, all rats received a $40-\mathrm{min}$ exposure to the plain, control, and enhanced contexts in a three-phase procedure. The order of exposure to the plain and enhanced contexts was counterbalanced within each ISI group. The rats were returned to holding cages for $40 \mathrm{~min}$ between each context exposure. In the final phase, the UP, 0 -sec, and 20 -sec ISI groups received eight US presentations on a VT 5-min schedule in the context to which they had yet to be exposed (plain or enhanced). The CS was presented (1) inmediately preceding the US in the 0 -sec ISI condition, (2) $20 \mathrm{sec}$ prior to the US in the $20-\mathrm{sec}$ ISI condition, or (3) on a random schedule with the constraint that a CS never occurred within $100 \mathrm{sec}$ of the US in the UP condition. The context control group received eight CS-only presentations on the same temporal schedule as did experimental animals. The rats were individually tested $24 \mathrm{~h}$ later in the context in which the CS had been presented.

\section{Results and Discussion}

Context conditioning. Figure 3 shows the time required to reach the first 100 pre-CS activity counts as a function of training condition in preweanling rats. Little, if any, context conditioning occurred in any group. Only a trend existed for longer latencies when training occurred in the enhanced context. A two-factor ANOVA (group $\times$ context condition) of the time to reach the first 100 pre-CS activity counts revealed only a significant main effect of context $[F(1,88)=4.28, p<.04]$, which was attributed to longer latencies to reach criterion among rats conditioned in the enhanced context.

CS conditioning. Data analysis for CS conditioning differed from Experiment $1 \mathrm{~A}$ in terms of the baseline 
period used to calculate suppression scores. Because no group differences existed in the 100 pre-CS counts prior to CS onset, comparable and stable baseline activity levels occurred across groups. Therefore, suppression score conversions used the last 100 pre-CS counts as the baseline measure.

Figure 4 shows mean suppression scores in the six training conditions. Conditioning to the CS occurred only with a 0 -sec trace interval, and even this was weak. Conditioning to the CS was independent of context saliency and was not evident with a 20-sec trace interval between CS-US presentations. A two-factor ANOVA (group $\times$ context) yielded only a significant main effect of group $[F(2,66)=7.49, p<.0012]$, indicating that the 0 -sec trace interval groups had significantly lower activity levels than did all other groups.

Preweanlings showed generally impaired conditioning relative to adults. Both context and CS conditioning were weak in preweanlings, not only relative to adults, but compared with other tests with preweanlings. Previous studies with similar procedures and parameters (including the use of home-cage shavings for preweanlings) reported stronger conditioning to both context and CS (Goodwin et al., 1992; McKinzie \& Spear, 1991) and generally equivalent CS conditioning for preweanlings and adults (see Kraemer \& Spear, 1990).

One important distinction between the present report and previous studies is the preconditioning experience, which consisted of exposure to three different contexts prior to CS-US training. This aspect of the procedure

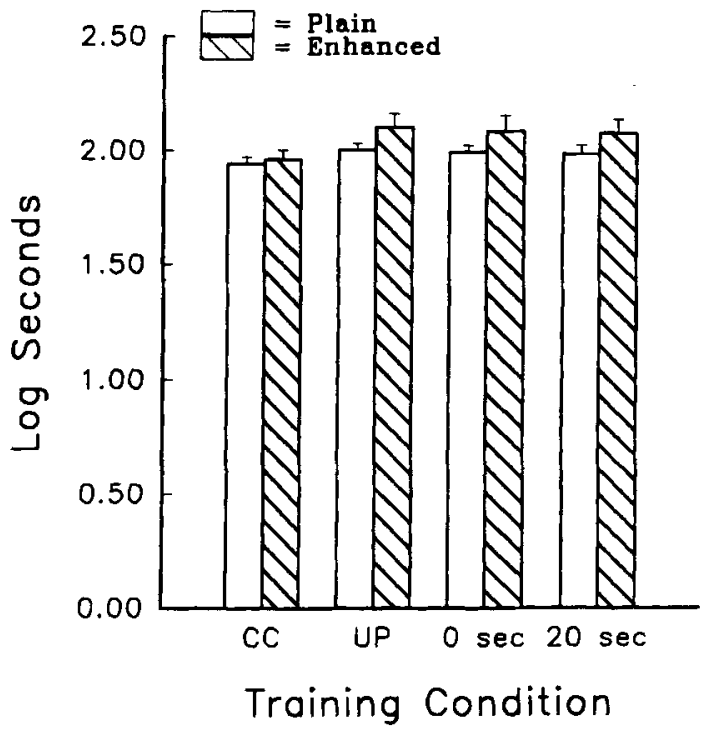

Figure 3. Mean time (log sec) to reach the first 100 pre-CS activity counts as a function of CS-US interval and context saliency in preweanling rats. Training consisted of eight CS and US presentations. Testing occurred 24 h later. The difference between context control (CC) groups and unpaired (UP), 0-sec, and 20-sec trace groups represents the degree of context conditioning. Higher latency values denote greater context conditioning. Vertical lines represent standard errors of the mean.

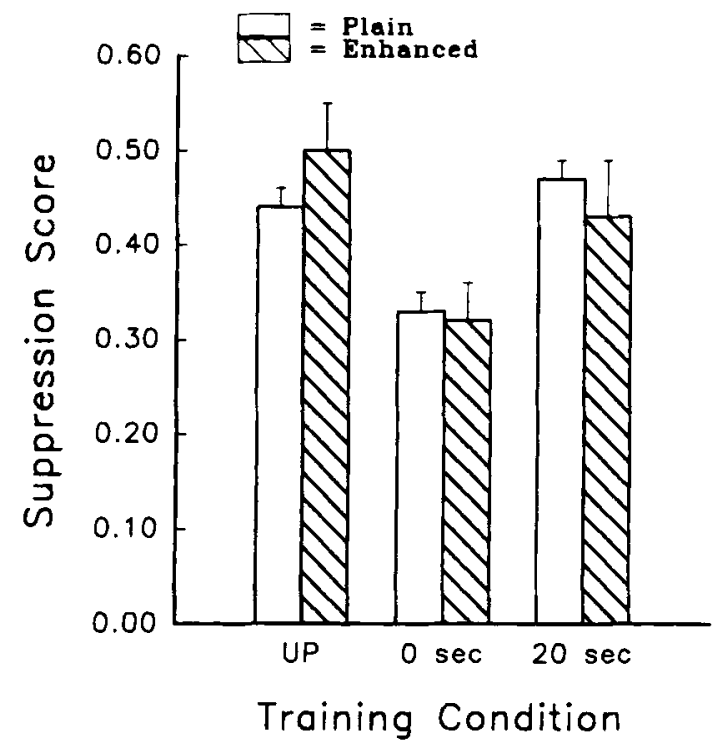

Figure 4. Suppression score conversions of the first $100 \mathrm{CS}$ activity counts as a function of CS-US interval and context saliency in preweanling rats. Training consisted of eight $C S$ and US presentations. Testing occurred $24 \mathrm{~h}$ later. The difference between unpaired (UP) and trace interval (0-sec and 20-sec) groups represents the degree of CS conditioning. Lower suppression scores denote greater conditioning to the $C S$. Vertical lines represent standard errors of the mean.

required a long period $(160 \mathrm{~min})$ of isolation from the home nest. The consequences of such a period of isolation from the home cage are known to be profound for preweanlings (Hofer, 1980). Younger rats also tend to be disrupted when a context shift is implemented between training and testing (Lariviere et al., 1990; Solheim et al., 1980). These aspects of the present procedure may have been especially detrimental to subsequent conditioning in young rats.

\section{EXPERIMENT 2A Preweanlings}

Experiments $2 \mathrm{~A}$ and $2 \mathrm{~B}$ used procedures that were modified slightly from those of Experiments $1 \mathrm{~A}$ and $1 \mathrm{~B}$ to again address the interactions among the CS, US, and context as a function of CS-US interval and context saliency. We sought to eliminate the apparent interference with context and CS conditioning in preweanlings, which may have resulted from the extensive preexposure to other contexts in Experiment 1B, by reducing the amount and duration of context preexposure. Preweanlings (Experiment 2A) and adults (Experiment 2B) were exposed only to the novel context and then immediately conditioned in either the plain or the enhanced context using the same four conditions from Experiments 1A and $1 \mathrm{~B}$ (UP, 0 -sec, $20-\mathrm{sec}$ or $80-\mathrm{sec}$, and context controls). A total of 16 , rather than eight, training trials also were given in an attempt to strengthen conditioning. 
Preweanlings were examined in this experiment because their performance was unexpectedly impaired in Experiment 1B. Parameters found to support conditioning in the preweanlings were then used to test adults under comparable circumstances in Experiment 2B.

\begin{abstract}
Method
Subjects and Apparatus. Seventy-seven male and female 17-day-old preweanling rats were reared under conditions identical to those used in Experiment 1B. A minimum of four litters were represented in each group ( $n=9-10$ per group). The contexts designated as plain, enhanced, and control were the same as in Experiments $1 \mathrm{~A}$ and $1 \mathrm{~B}$, with the exception that the ambient odor in the enhanced context was $1 \mathrm{ml}$ of Virginia Dare banana extract.

Procedure. Preweanling rats were assigned randomly to one of eight groups of 9-10 rats each. UP, $0-\mathrm{sec}$, and $20-\mathrm{sec}$ ISI groups initially received a $64-\mathrm{min}$ exposure to the control context. Context controls received unsignaled footshocks during this period. Immediately following exposure to the control context, the UP, 0 -sec, and 20-sec ISI groups received CS and US presentations in either the plain or the enhanced context. All aspects of this phase of the procedure were identical to Phase 3 training in Experiment $2 \mathrm{~B}$ except that 16 training trials were used in an attempt to obtain stronger conditioning. Trials were presented on a VT 4-min schedule (from US-US). Context controls received only presentations of the CS in either the plain or the enhanced context during this phase. The sensitivity of the activity monitor was identical to that of Experiment 1B. Testing occurred $24 \mathrm{~h}$ after training and was conducted as described in Experiments $1 \mathrm{~A}$ and $1 \mathrm{~B}$.
\end{abstract}

\section{Results and Discussion}

Context conditioning. Figure 5 shows the amount of time required to reach the first 100 activity counts dur-

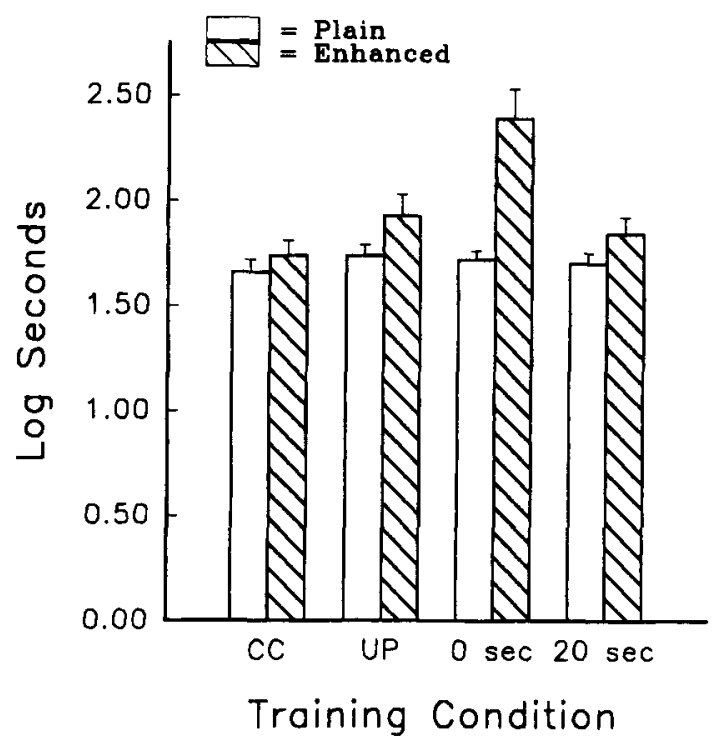

Figure 5. Mean time (log sec) to reach the first 100 pre-CS activity counts as a function of CS-US interval and context saliency in preweanling rats. Training consisted of $16 \mathrm{CS}$ and US presentations. Testing occurred $24 \mathrm{~h}$ later. The difference between context control (CC) groups and unpaired (UP), 0-sec, and 20-sec trace groups represents the degree of context conditioning. Vertical lines are standard errors of the mean. ing the test session as a function of training condition. Longer latencies (stronger context conditioning) were evident in the 0 -sec trace group that was trained in the enhanced context. A trend toward conditioning also was apparent in the UP group trained in the enhanced context, but no other groups differed from context controls.

The ANOVA (group $\times$ context) yielded significant main effects of group $[F(3,69)=7.85, p<.0001]$ and context $[F(1,69)=18.97, p<.0001]$. The group $\times$ context interaction also was statistically significant $[F(3,69)=5.39, p<.002]$. A Fisher test showed that the 0 -sec trace group that was conditioned in the enhanced context had longer latency scores than did all other groups. Moreover, the UP group conditioned in the enhanced context had a longer latency than did the context control group conditioned in the plain context. The difference between the UP and context control plaincontext groups did not attain a conventional level of statistical significance $(p<.06)$.

In summary, strongest context conditioning occurred with no delay imposed between CS-US presentations. This outcome is especially striking given that the UP group trained in the enhanced context, which showed the strongest context conditioning in adults in Experiment $1 \mathrm{~A}$, showed only borderline conditioning to the context in the present experiment.

CS conditioning. The last 100 pre-CS counts were analyzed for differences among ISI groups and context conditions. The ANOVA yielded a significant main effect of context $[F(1,57)=15.03, p<.0004]$, but no main effect of group or interaction between variables. Thus, stable baselines were inferred for groups within each context condition, and suppression scores were calculated as in Experiment 1B.

Figure 6 shows mean suppression scores as a function of ISI and context conditions. Strong CS conditioning occurred in the 0 -sec trace groups regardless of context saliency. Conditioning also occurred in the enhanced (but not plain) context when the ISI was $20 \mathrm{sec}$.

A two-factor ANOVA (group $\times$ context condition) of suppression scores yielded main effects of group $[F(2,55)=33.28, p<.0001]$ and context $[F(1,55)=$ $5.19, p<.03$ ], as well as a significant group $\times$ context interaction $[F(2,55)=3.53, p<.04]$. A Fisher test conducted on the interaction revealed that both 0 -sec trace groups and the 20 -sec trace group conditioned in the enhanced context had lower suppression scores than did UP controls. The 0 -sec trace group trained in the enhanced context had a lower suppression score than did the 20-sec enhanced context group.

These data suggest that the context and CS did not compete for conditioning to the US in preweanlings. Instead, learning about the context was potentiated by conditioning to the CS.

For example, strongest context conditioning was found in the 0-sec trace group, which also exhibited strongest CS learning. Although there was a reciprocal enhancement of CS learning by strong context in the 0 -sec trace group, caution must be used in interpreting 


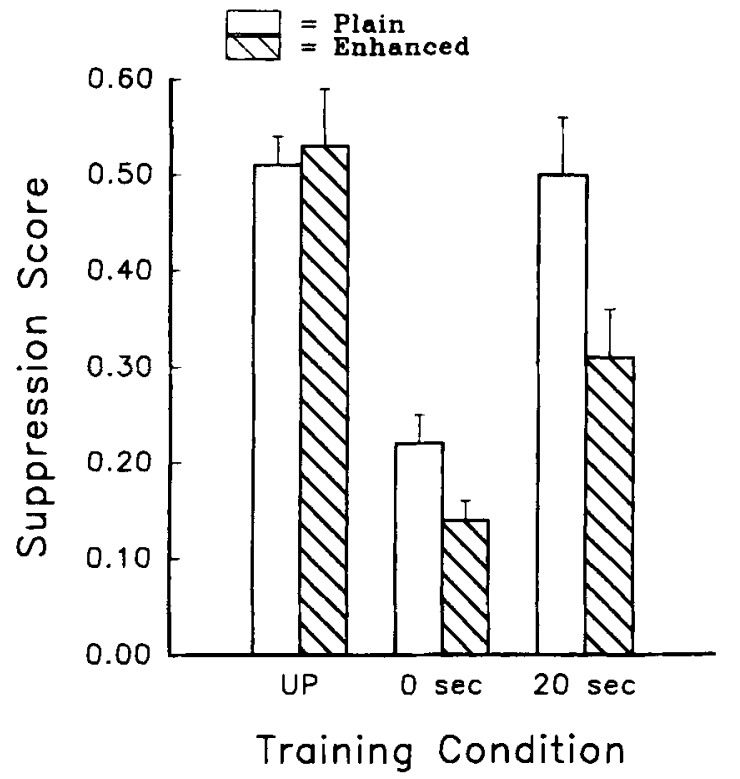

Figure 6. Suppression score conversions of the first $100 \mathrm{CS}$ activity counts as a function of CS-US interval and context saliency in preweanling rats. Training consisted of $16 \mathrm{CS}$ and US presentations. Testing occurred $24 \mathrm{~h}$ later. The difference between unpaired (UP) and trace interval (0-sec and 20-sec) groups represents the degree of CS conditioning. Vertical lines are standard errors of the mean.

these results since the CS was not tested independently of the training context. To conclude, potentiation of context conditioning by CS conditioning was established by comparison with context conditioning tested in the $\mathrm{ab}$ sence of the CS, and the enhancement of CS responding could be at least partially due to $\mathrm{CS}$-context summation.

\section{EXPERIMENT 2B Adults}

In Experiment 2B, we trained and tested adult rats using the parameters and procedures of Experiment $2 \mathrm{~A}$. This procedure yielded stronger conditioning and clearer group differences in preweanlings than did those used in Experiment $1 \mathrm{~B}$. We predicted that adults would again express CS-context competition based on the results of Experiment 1A. Upaired (UP), 0-sec, and 80-sec ISI groups were given 16 training trials in either plain or enhanced sensory contexts, and context controls received CS only presentations. Testing occurred $24 \mathrm{~h}$ later in the context in which the CS had been presented.

\section{Method}

Subjects and Apparatus. Sixty-four male and female adult rats were bred and reared in the same manner as described in Experiment 1A. The apparatus was the same as that used in Experiment $1 \mathrm{~A}$ with the exception that clean newspapers, rather than pine shavings from the home cage, rested beneath the shock grid of the plain context.

Procedure. The rats were assigned randomly to one of eight groups of 8 rats each. As in Experiment 2A, all groups first received exposure to the control context, followed immediately by exposure to the training (plain or enhanced) context. Context and CS conditioning were assessed $24 \mathrm{~h}$ later in the context in which the CS had been presented.

\section{Results and Discussion}

Context conditioning. Figure 7 shows mean latencies to reach the first 100 activity counts during testing as a function of CS-US interval and context saliency in adult rats. UP and 80 -sec trace groups generally displayed longer latencies (greater fear conditioning) to reach criterion than did the 0 -sec trace and context control groups. The influence of context saliency was minimal, except in the 80-sec trace condition in which the enhanced context promoted greater context fear than did the plain context.

These observations were supported statistically. A two-factor ANOVA (group $\times$ context) yielded a main effect of group $[F(3,56)=7.04, p<.0004]$. A subsequent Fisher test revealed that UP and 80-sec trace groups took longer than did the context control groups to reach criterion. The UP condition also had a longer mean latency than did the 0-sec trace group. As in Experiment 1A, context conditioning was weakest in the condition that was most likely to promote CS conditioning.

CS conditioning. A two-factor ANOVA (group $\times$ context) on latencies to reach 100 activity counts prior to CS presentations yielded a main effect of group $[F(3,56)=6.56, p<.0007]$. Thus, to establish a stable baseline period, it was found that all groups except the UP group trained in the plain context and 80 -sec enhanced groups had less than a $15 \%$ change during the

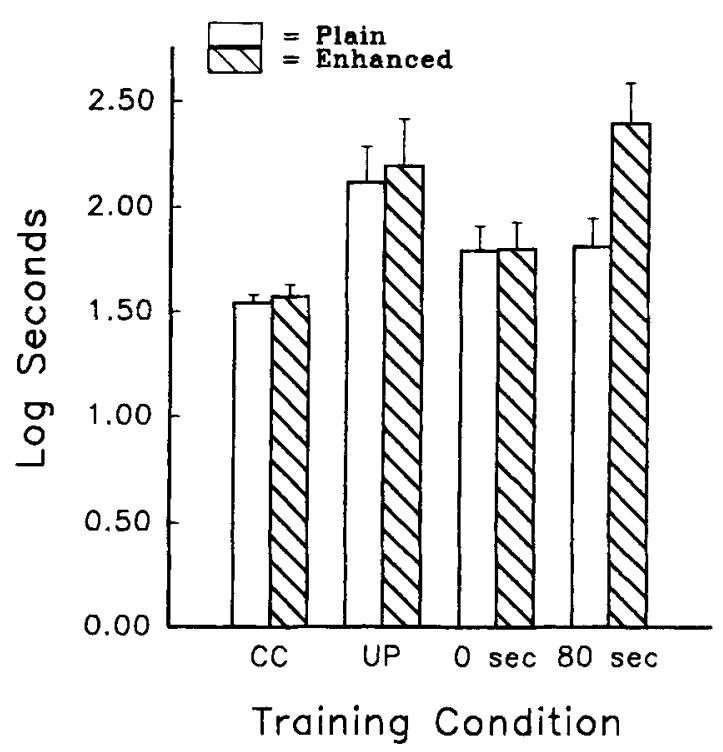

Figure 7. Mean time (log sec) to reach the first 100 pre-CS activity counts as a function of CS-US interval and context saliency in adult rats. Training consisted of $16 \mathrm{CS}$ and US presentations. Testing occurred $24 \mathrm{~h}$ later. The difference between context control $(\mathrm{CC})$ groups and unpaired (UP), 0-sec, and 80-sec trace groups represents the degree of context conditioning. Vertical lines are standard errors of the mean. 


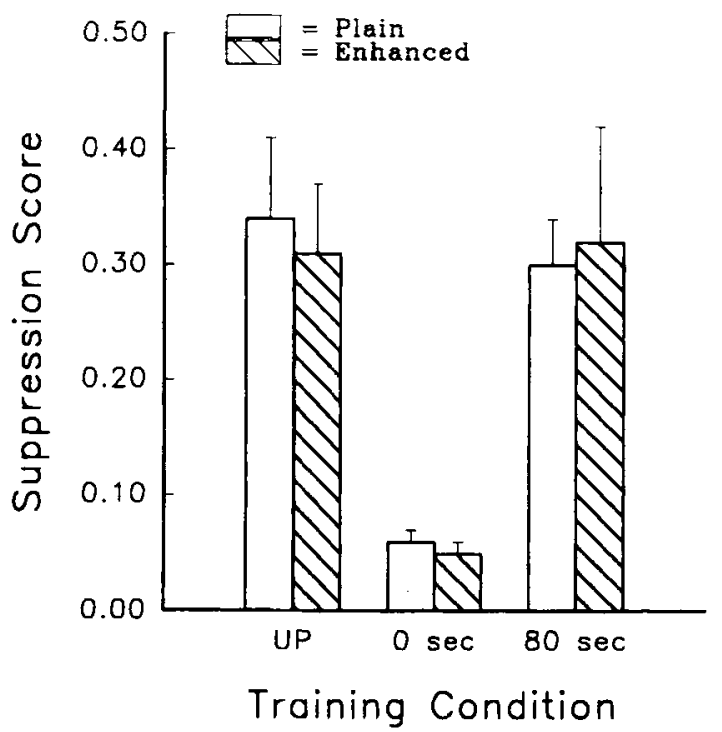

Figure 8. Suppression score conversions of the first $100 \mathrm{CS}$ activity counts as a function of CS-US interval and context saliency in adult rats. Training consisted of $16 \mathrm{CS}$ and US presentations. Testing occurred $24 \mathrm{~h}$ later. The difference between unpaired (UP) and trace interval (0-sec and 80-sec) groups represents the degree of CS conditioning. Vertical lines are standard errors of the mean.

last 50 counts. The CS period therefore was analyzed as in Experiment 1A. While the last two blocks of these groups did exceed a $15 \%$ change criteria, the means were within one standard deviation of each other. This suggests that when the variance within each block was taken into account, the means of these two blocks did not differ to a great extent.

Figure 8 shows mean suppression scores as a function of CS-UCS interval and context saliency. The consequence of doubling the number of CS-US training trials was to uniformly increase responding to the CS. The increased CS conditioning abolished any influence of context saliency.

The context $\times$ group ANOVA yielded only a main effect of group $[F(2,43)=11.39, p<.0001]$. The source of the group main effect was the greater suppression of activity in the presence of the CS for the 0 -sec trace conditions relative to the UP and $80-\mathrm{sec}$ trace conditions.

The results of Experiment 2B generally support the CS-context competition seen in Experiment 1A. The 0 -sec trace groups showed the most conditioning to the CS and the least conditioning to the context; the opposite relationship held for groups with less contiguity or contingency between CS and US (80-sec trace and UP groups). Context saliency did not influence responding to the context or the CS to the extent observed in Experiment IA. The conditions of the present experiment that were changed from Experiment $1 \mathrm{~A}$-less preconditioning exposure to various contexts and double the number of CS-US trials-produced CS learning strong enough to mask the influence of context saliency.

\section{GENERAL DISCUSSION}

Adult rats behaved in a manner that is consistent with the view that the context and the CS compete for conditioning to the US. Responding to either the context or the CS occurred at the expense of responding to the other element. Preweanling rats did not exhibit competitive stimulus selection; instead, they behaved as if the context and the US were complementary or even synergistic. Preweanlings expressed stronger conditioning to the context when conditioning to CS was relatively strong (and vice versa). Although this effect was less apparent in Experiment 1B than in Experiment 2A, it is consistent with expectations based on other observations concerning preweanling learning (e.g., Kucharski \& Spear, 1985; Lariviere et al., 1990; Mellon et al., 1991; Spear et al., 1988), as well as previous experiments with preweanlings that used similar stimuli and procedures (Goodwin et al., 1992; McKinzie \& Spear, 1991).

Adult rats responded to the CS and context elements of the training episode in a competitive manner prescribed by many conventional theories of conditioning (Rescorla \& Wagner, 1972). Manipulations that mitigated conditioning to the CS (long CS-US interval, weak CS-US contingency and, to some extent, a salient enhanced context) resulted in strong responding to the context, whereas conditions that promoted strong CS learning (greater contiguity or contingency between CS and US) weakened context conditioning. In comparison with the results of Experiment 1A, the results of Experiment $2 \mathrm{~B}$ suggested that the influence of one variable (context saliency) may be attenuated by inflating the value of another (CS conditioning via number of CS-US training trials). These data support the view that older animals tend to respond to their environment rather selectively and that increased processing of one stimulus is often at the expense of another.

Preweanlings did not show stimulus selection comparable to that of adults. Young rats appeared instead to unitize CS and context learning, so that an enhancement of context learning occurred when CS learning was strong. Although the increased responding to the CS as a result of context conditioning could be attributed to either potentiation of CS by context or summation of CS conditioning with context conditioning, this enhancement effect in preweanlings is nevertheless of theoretical interest.

Possible sources of ontogenetic differences in stimulus selection have been widely considered (Rudy, 1991; Spear, 1979, 1984; Spear et al., 1988; Spear \& McKinzie, 1994; Turkewitz \& Mellon, 1989). The present results may be understandable in terms of a particular age-related distinction between modal and amodal stimulus processing (Gibson, 1983; Lewkowicz, 1991; Spear \& McKinzie, 1994; Spear \& Molina, 1987; Turkewitz, Lewkowicz, \& Gardner, 1984). By modal processing, we mean the encoding of energy-specific attributes of a 
given learning situation, in which the organism differentiates between stimuli on the basis of the sensory modality used to process each stimulus. In contrast, an animal is said to encode amodally if it processes attributes that are orthogonal to the source of energy of a stimulus, such as affect, contiguity, net intensity, or familiarity. Such properties are not unique to a specific sensory system. Given the sequential sensory development of most altricial animals (Alberts, 1984; Gottlieb, 1971), it may be especially beneficial for infant organisms to process stimuli amodally since modal properties of objects and events change rapidly with the addition of new sensory capabilities.

An example of possible amodal versus modal processing is reported in a series of studies by Mellon et al. (1991). In one experiment, a simultaneous light and 48-dB tone was paired with a US, and then testing occurred to only a 73- or 48-dB tone. Whereas preweanlings showed significantly stronger conditioning to the 73-dB tone than to the 48-dB tone, the opposite relationship occurred in adults. Adults responded best to the 48-dB tone that was part of the original training compound. In terms of a modal versus amodal processing account of stimulus selection, adults attended to the qualitative aspects of the training and testing stimuli (i.e., frequency) and preweanlings responded to quantitative properties (i.e., net intensity). Adults responded best when the tone-alone test stimulus was the same as the tone trained in compound with the light. Preweanlings responded strongly when the test tone was more intense and, hence, more similar in net intensity to the combination of light and less intense tone.

Within the framework of the present study, adults responded selectively and competitively to the elements of the training episode, in accord with how well the context of CS alone predicted the US. Preweanlings, however, processed the context and CS more equivalently. For the preweanlings, better learning of either the context or the CS appeared to reciprocally promote learning of the other element. Instead of being fearful of a tone paired with a footshock in a bright, odorous compartment, younger animals may have become fearful of a bright, odorous, and loud place - the subtle difference being that the preweanlings unitized the occurrence of the tone CS and the fearful context. The finding that preweanlings conditioned most strongly when trained in an enhanced context and with a 0 -sec trace interval could be explained in terms of the amodal attribute of net intensity. Strongest learning occurred in this condition because the perceived intensity of the tone was configured additively to that of the context, resulting in an especially salient reinforced stimulus. We cannot dismiss the possibility that adults also processed the context and the CS in a similar configural manner (e.g., Pearce, 1987), and we have suggested elsewhere that adults may in some circumstances revert to infantile processing of this kind (e.g., Spear et al., 1988). But nevertheless, the beneficial influence of stimulus intensity would be expected to be greater for preweanlings than for adults (Mellon et al., 1991).
An amodal encoding interpretation based on net intensity may help explain the absence of potentiation when training took place in the plain context. In order for potentiation to occur, the degree of learning accrued during compound stimulus training must exceed the loss due to generalization decrement. The enhanced training context combined with the intensity of the CS produced learning strong enough to compensate for any generalization decrement produced by testing the context alone. Training in the plain context, however, apparently did not contribute enough to the overall net intensity to offset generalization decrement.

This account also explains the absence of CS conditioning in the plain context when a long trace interval was imposed. The combined net intensity of the plain context and trace CS was inadequate to support conditioning. Conversely, an enhanced context can compensate for even a weak CS and a long trace interval, resulting in a net intensity that supported conditioning. Note that context conditioning was not found in this case, presumably because the configuration was not of a sufficient intensity to overcome generalization decrement.

In conclusion, these studies further delineate ontogenetic differences in stimulus selection processes. It is proposed that the infant rat encodes information in a manner unlike that of the adult rat. Whereas the adult animal may perceive the environment as being composed of select constituents to which processing may be allocated as deemed appropriate, the infant organism may unitize these multitudinous elements into a configural representation based upon amodal properties. Only with sensory maturation and experience do infants become disposed to engage in selective, modal-based processing.

\section{REFERENCES}

ALberts, J. R. (1984). Sensory-perceptual development in the Norway rat: A view toward comparative studies. In R. Kail \& N. E. Spear (Eds.), Comparative perspectives on the development of memory (pp. 65-101). Hillsdale, NJ: Erlbaum.

ANNAU, Z., \& KAMIN, L. J. (1961). The conditioned emotional response as a function of intensity of the US. Journal of Comparative \& Physiological Psychology, 54, 428-432.

Bolles, R. C., \& Collier, A. C. (1976). The effect of predictive cues on freezing in rats. Animal Learning \& Behavior, 4, 6-8.

FANSELOW, M. S. (1980). Conditional and unconditional components of post-shock freezing. Pavlovian Journal of Biological Sciences, $15,177-182$.

Gibson, E. J. (1983). Principles of perceptual learning and development. New York: Appleton-Century-Crofts.

Goodwin, G. A., Heyser, S. J., Moody, C. A., Rajachandran, L., Molina, V. A., Arnold, H. M., McKinzie, D. L., Spear, N. E., \& SPEAR, L. P. (1992). A fostering study of the effects of prenatal exposure: II. Offspring behavioral measures. Neurotoxicology \& Teratology, 14, 423-432.

GotTlieb, G. (1971). Ontogenesis of sensory function in birds and mammals. In E. Tobach, L. R. Aronson, \& E. Shaw (Eds.), The biopsychology of development (pp. 67-128). New York: Academic Press.

Hinderliter, C. F., \& Misanin, J. R. (1988). Weanling and senescent rats process simultaneously presented odor and taste differently than young adults. Behavioral \& Neural Biology, 49, 112-117.

HOFER, M. A. (1980). Toward a developmental basis for disease predisposition: The effect of early maternal separation on brain, be- 
havior, and cardiovascular system. In H. Weinder, M. A. Hofer, \& A. J. Stunkard (Eds.), Brain, behavior and bodily disease (pp. $209-$ 228). New York: Raven Press.

KePPEL, G. (1982). Design and analysis: A researcher's handbook (2nd ed.). Englewood Cliffs, NJ: Prentice-Hall.

Kraemer, P. J., Lariviere, N. A., \& Spear, N. E. (1988). Increase in retention of a taste aversion by preweanling rats after a long interval. Animal Learning \& Behavior, 16, 185-190.

Kraemer, P. J., \& SPEAR, N. E. (1990). Preweanling and adult rats treat conditioned light-tone combinations differently. Animal Learning \& Behavior, 18, 113-123.

KucharSKi, D., \& SPEAR, N. E. (1985). Potentiation and overshadowing in preweanling and adult rats. Journal of Experimental Psychology: Animal Behavior Processes, 11, 15-34.

Lariviere, N. A., Chen, W.-J., \& SPEAR, N. E. (1990). The influence of olfactory context on Pavlovian conditioning and its expression in preweanling (16-day-olds) and in adult rats. Animal Learning \& Behavior, 18, 179-190.

LEwkowicz, D. J. (1991). Development of intersensory functions in human infancy: Auditory/visual interactions. In M. J. S. Weiss \& P. R. Zelazo (Eds.), Newborn attention: Biological constraints and the influence of experience (pp. 308-338). Norwood, NJ: Ablex.

MarLin, N. A. (1981). Contextual associations in trace conditioning. Animal Learning \& Behavior, 9, 519-523.

McKinzie, D. L., Lee, J., Bronfen, J. H., Spear, L. P., \& Spear, N. E. (1994). Context and tone conditioning are selectively impaired by ethanol in the preweanling rat: Effects of dose and time of administration. Behavioral \& Neural Biology, 62, 201-209.

McKinZIE, D. L., \& SpeAR, N. E. (1991, May). Potentiation of context conditioning by $C S$ conditioning in preweanling rats as a function of CS-US interval. Paper presented at the meeting of the Midwestern Psychological Association, Chicago.

Mellon, R. C., Kraemer, P. J., \& Spear, N. E. (I991). Development of intersensory function: Age-related differences in stimulus selection of multimodal compounds in rats as revealed by Pavlovian conditioning. Journal of Experimental Psychology: Animal Behavior Processes, 17, 448-464.

Moye, T. B., \& Rudy, J. W. (1985). Ontogenesis of learning: VI. Learned and unlearned responses to visual stimulation in the infant rat. Developmental Psychobiology, 18, 395-409.

MOYE, T. B., \& RUDY, J. W. (1987). Ontogenesis of trace conditioning in young rats: Dissociation of associative and memory processes. Developmental Psychobiology, 20, 405-414.

ODling-Smee, F. J. (1975). The role of background stimuli during Pavlovian conditioning. Quarterly Journal of Experimental Psychology, 27, 201-209.

Pavlov, I. P. (1927). Conditioned reflexes (G. V. Anrep, Trans.). London: Oxford University Press.
Pearce, J. M. (1987). A model for stimulus generalization in Pavlovian conditioning. Psychological Review, 94,61-73.

Rescorla, R. A., \& WAGNer, A. R. (1972). A theory of Pavlovian conditioning: Variations in the effectiveness of reinforcement and nonreinforcement. In A. H. Black \& W. F. Prokasy (Eds.), Classical conditioning II: Current research and theory (pp. 64-99). New York: Appleton-Century-Crofts.

RUDY, J. W. (1991). Elemental and configural associations, the hippocampus and development. Developmental Psychobiology, 24, 221-236.

Solheim, G. S., Hensler, J. G., \& Spear, N, E, (1980). Age-dependent contextual effects on short-term active avoidance retention in rats. Behavioral \& Neural Biology, 30, 250-259.

SPEAR, N. E. (1979). Memory storage factors in infantile amnesia. In G. H. Bower (Ed.), The psychology of learning and motivation (Vol. 13, pp. 91-154). New York: Academic Press.

SPEAR, N. E. (1984). Ecologically determined dispositions control the ontogeny of learning and memory. In R. Kail \& N. E. Spear (Eds.), Comparative perspectives on the development of memory (pp. 325358). Hillsdale, NJ: Erlbaum.

Spear, N. E., Kraemer, P. J., Molina, J. C., \& Smoller, D. E. (1988). Developmental change in learning and memory: Infantile disposition for unitization. In J. Delacour \& J. C. S. Levy (Eds.), Systems with learning and memory abilities (pp. 27-52). Amsterdam: Elsevier, North-Holland.

SPEAR, N. E., \& KUCHARSKI, D. (1984). Ontogenetic differences in the processing of multi-element stimuli. In H. Roitblat, T. Bever, \& H. Terrace (Eds.), Animal cognition (pp. 545-567). Hillsdale, NJ: Erlbaum.

SPEAR, N. E., \& McKinzIE, D. L. (1994). Intersensory integration in the infant rat. In D. J. Lewkowicz \& R. Lickliter (Eds.), The development of intersensory perception: Comparative perspectives (pp. 133-161). Hillsdale, NJ: Erlbaum.

SPEAR, N. E., \& Molina, J. C. (1987). The role of sensory modality in the ontogeny of stimulus selection. In N. Krasnegor, E. M. Blass, M. A. Hofer, \& W. P. Smotherman (Eds.), Perinatal development: A psychobiological perspective (pp. 83-110). Orlando, FL: Academic Press.

Turkewitz, G., Gardner, J. M., \& Lewkowicz, D. J. (1984). Sensory/ perceptual functioning during early infancy: The implications of a quantitative basis for responding. In B. Greenberg \& E. Tobach (Eds.), Behavioral evolution and integrative levels (pp. 167-195). Hillsdale, NJ: Erlbaum.

TuRKewitz, G., \& Mellon, R. C. (1989). Dynamic organization of intersensory function. Canadian Journal of Psychology, 43, 286-301.

(Manuscript received August 23, 1993; revision accepted for publication September 1, 1994.) 